\title{
La Constitución ecuatoriana entre el multiculturalismo y la interculturalidad. Un análisis de su orientación
}

\section{The ecuadorian constitution between multiculturalism and interculturality. An analysis of its orientation}

Germán Gerson Huayamave

Universidad Santa María, Ecuador

Autor por Correspondencia: ghuayamaveo@usm.edu.ec

Fecha de recepción: 7 de Marzo de 2017 - Fecha de aceptación: 5 de Junio de 2017

Resumen: Este ensayo efectúa un análisis sobre la orientación que guarda la actual constitución ecuatoriana desarrollada entre dos doctrinas; por una parte, el multiculturalismo respecto a las distintas culturas que se pueden apreciar en el territorio nacional, considerando además las debidas reparaciones ante el olvido experimentado por amplios grupos de ecuatorianos en estado de vulnerabilidad; y por otra parte, la interculturalidad como perspectiva que fomenta la convivencia entre connacionales de múltiple ascendencia. Determinar que esta política de reconocimientos favorecerá leyes sectoriales bajo el subterfugio de reivindicación y reparación hacia los grupos vulnerables, de manera particular hacia aquel sector de la población indígena ecuatoriana cuyo respaldo fue comprometido abiertamente con el entonces candidato Rafael Correa y que hoy en día continúa en espera de mejores días; como indicara el lema de presentación de la carta magna aprobada, para que deliberadamente ¡Dejemos el pasado atrás!

Palabras clave: multiculturalismo; interculturalidad; constitución; derechos; pueblo indígena

\begin{abstract}
This essay analyzes the orientation of the current Ecuadorian constitution developed between two doctrines; On the one hand, the multiculturalism with respect to the different cultures that can be seen in the national territory, considering also the due repairs before the oblivion experienced by large groups of Ecuadorians in a state of vulnerability; And on the other hand, interculturality as a perspective that fosters the coexistence of multiple ancestry. To determine that this recognition policy will favor sectoral laws under the subterfuge of vindication and reparation towards vulnerable groups, in particular towards that sector of the Ecuadorian indigenous population whose backing was openly committed with the then candidate Rafael Correa and that today continues in Hope for better days; As indicated by the motto of presentation of the approved letter, so that we deliberately leave the past behind!
\end{abstract}

Key words: multiculturalism; interculturalism; constitution; rights; indigenous people 


\section{Introducción}

Con la elección como presidente del economista Rafael Correa en el año 2007 y en atención a los ofrecimientos manifestados a los grupos que le respaldaron, de manera especial a las comunidades indígenas del Ecuador, se convoca a la conformación de una Asamblea Constituyente, en reemplazo del Congreso Nacional, esta asamblea aprueba un año después, la actual Constitución nacional vigente desde octubre del 2008. La carta magna ecuatoriana surge como respuesta al abandono que soportaban las colectividades más vulnerables, tales como las comunidades, pueblos y nacionalidades indígenas, los afroecuatorianos y los montubios de la zona rural costera.

Una Constitución que aumentaba las expectativas y anhelos de estos grupos vulnerables y se comprometía a permitirles alcanzar por medio de la garantía de sus derechos, el Buen Vivir o Sumak Kawsay ${ }^{1}$. La construcción de una nueva forma de convivencia ciudadana, de una sociedad que respeta, en todas sus dimensiones, la dignidad de las personas y las colectividades, consagra así al Ecuador como un estado constitucional e intercultural. Sin embargo, no pasa desapercibida la influencia del multiculturalismo y su posterior adecuación para fomentar la interacción y el diálogo entre los ecuatorianos.

Esta investigación pretende analizar la Constitución ecuatoriana y sus aspectos más significativos en cuanto al multiculturalismo y la interculturalidad; sin dejar de considerar que el multiculturalismo tiene grandes dificultades para insertarse en el Constitucionalismo, ya que sus presupuestos, valores y contenidos normativos son contrarios (Cossío, 2000, pág. 76) o al darnos cuenta el problema que se presentaba, como indica Ruiz, ya que pese a la retórica y a la ya manida acusación de etnocentrismo, la libertad política y la idea constitucional nacieron en el contexto de una cultura (la cultura europea, occidental o cristiana) y solo han sido asumidas por algunas culturas, pero no por todas. (Ruiz, 2001, pág. 20) Además se deberá tener en cuenta, que la "política del reconocimiento" de las culturas que exige el multiculturalismo implica leyes “sectoriales" y, por tanto, desiguales (Ruiz, 2001, pág. 21).

Sin embargo, bajo este panorama la Asamblea Nacional aprueba la Constitución de la República del Ecuador en el mes de octubre del 2008 bajo un lema por demás simbólico "Dejemos el pasado atrás", acaso como una manera de afirmar aspectos que guardan relación con la reivindicación y reparaciones para los grupos más vulnerables.

\section{Respecto del Multiculturalismo}

\section{Desarrollo}

Para poder efectuar el análisis propuesto en la carta magna ecuatoriana, se iniciará contextualizando y definiendo el planteamiento multiculturalista. En primer lugar debemos considerar la apreciación dada por Taylor, quien se aparta de las polémicas políticas para ofrecer lo que está en juego en la actualidad, la exigencia de la identidad particular, que es base para la construcción de una teoría política multicultural. Pero esta identidad sin importar la raza, el sexo, la religión, requiere de reconocimiento y de un trato igual ante todos, se trata de ir más allá, presupone que hombres de distintas culturas puedan coexistir, puedan crecer en un mundo

\footnotetext{
${ }^{1}$ En su significado original en idioma kichwa, Sumak hace referencia a la realización ideal y hermosa del planeta, mientras que kawsay significa una vida digna y en plenitud.
} 
paralelo y pensar en una realidad social basada en el respeto y la tolerancia, el reconocimiento del otro, del diferente. De esta forma cobra importancia la polémica del multiculturalismo. (Devia \& Romero, 2015, pág. 132)

Considerando además que cuando fue promulgado en 1971, el multiculturalismo ignoraba aspectos de desigualdad económica; quienes lo demandaban eran grupos de inmigrantes blancos, ucranianos, italianos, escandinavos, que ya eran económicamente exitosos en Canadá. Ellos querían el respeto a su etnicidad, no necesitaban igualdad de oportunidades porque ya la tenían. (Kymlicka, 2001, pág. 123) Era por tanto fundamental, indica el referido autor, que con una población multireligiosa y multiétnica, las instituciones públicas se adapten para poder cumplir equitativamente con sus funciones, para asegurar que no se discrimine, estigmatice o excluya a los inmigrantes (Kymlicka, 2001, pág. 121). Cabe mencionar que la situación de los indios y los inuit no era exactamente la misma que enfrentaban los inmigrantes canadienses.

Tras varias décadas del fenómeno multicultural en Canadá, se puede argumentar como menciona Kymlicka, que la adopción del multiculturalismo ha enriquecido la democracia incrementando el acceso político para grupos no dominantes, ha mejorado la libertad individual permitiendo opciones culturales antes prohibidas o estigmatizadas y mejoró la justicia remediando los efectos injustos de las jerarquías raciales y étnicas heredadas. En algunos países, con toda seguridad, también ha mejorado la paz, lo que impide el apoyo potencial a más movimientos revolucionarios en grupos no dominantes. (Kymlicka, 2007, pág. 31)

Podemos entender el multiculturalismo de dos maneras, expresa Sartori: por un lado, como un hecho, una expresión que registra la existencia de una multiplicidad de culturas; y por otro lado, como un valor, que implica una "política de reconocimiento" de las diversas culturas. Este "reconocimiento" exige que todas las culturas no sólo merezcan "respeto" (como en el pluralismo) sino un "mismo respeto", por la sencilla razón que para el multiculturalismo todas las culturas tienen "igual valor". Es precisamente con este último argumento que el autor italiano critica al multiculturalismo; atribuir a todas las culturas "igual valor" equivale a adoptar un relativismo absoluto que destruye la noción misma de valor. Sartori, como se citó en (Ruiz, 2001, pág. 7).

Así como Sartori, existen varios otros autores que efectúan críticas al multiculturalismo, Brian Barry menciona por ejemplo, que los objetivos universalistas e igualitarios que el liberalismo se propone son obstaculizados por las propuestas multiculturales; así también, que los multiculturalistas no se preocupan por erradicar las condiciones originales de desigualdad que existen en las relaciones entre grupos mayoritarios y minoritarios. Luego, Barry va más allá, al considerar que las propuestas multiculturales no sólo no intentan erradicar las condiciones originales de desigualdad permanentemente, sino que de algún modo refuerzan aquellas diferencias y desventajas. (Wierny, 2005, págs. 19-20)

Sánchez por su parte indica que el multiculturalista admite su forma de apreciar la convivencia entre culturas como la verdadera, como absoluta, como no relativa. De la constatación de la injusticia y de la opresión, aunque no siempre indagan correctamente sus causas ni determinan cabalmente a sus responsables, pasan al elogio de los valores y formas de vida de los oprimidos. (Sánchez, 2003, pág. 172) 
Una postura quizás desmedida al respecto nos presenta Zizek, quien manifiesta que el multiculturalismo es un racismo que vacía su posición de todo contenido positivo (el multiculturalismo no es directamente racista, no opone al Otro los valores particulares de su propia cultura), pero igualmente mantiene esta posición como un privilegiado punto vacío de universalidad, desde el cual uno puede apreciar (y despreciar) adecuadamente las otras culturas particulares: el respeto multiculturalista por la especificidad del Otro es precisamente la forma de reafirmar la propia superioridad. (Zizek, 1998, pág. 172)

Acaso el Ecuador se insertó en esta política de reconocimientos y reparaciones para con los grupos más vulnerables, de manera especial para con las comunidades indígenas, y por ende compone toda una nueva estructura constitucional que garantice su política, aunque dicho sea de paso, esta nueva estructura solo debería instaurar el punto de partida de una verdadera transformación en la sociedad ecuatoriana.

\section{En cuanto a la Interculturalidad}

Para fines del año 2008 en que se aprueba la Constitución ecuatoriana ya el multiculturalismo había transitado casi cuatro décadas de evolución, especialmente en países como Canadá y Australia; las fuertes críticas sobre esta doctrina permiten un nuevo desarrollo intelectual o quizás una perspectiva distinta y más amplia respecto al reconocimiento y a las reparaciones a los grupos afectados por la marginación, y en no pocos casos, por el abandono sufrido ante la inacción del Estado.

Se deberá reconocer entonces como una crítica adicional, la insuficiencia del planteamiento multicultural como proyecto de cohesión social de la comunidad política donde se ubican los diferentes. Considerando esta limitación, Giménez analiza la emergencia del nuevo paradigma interculturalista en campos diversos de la elaboración, la política pública y la intervención social. (Giménez, 2003, pág. 17) Su aportación específica está en el terreno de la interacción entre los sujetos o entidades culturalmente diferenciados. El multiculturalismo parece conformarse con la coexistencia, o en todo caso espera que la convivencia social surja del respeto y aceptación del otro; sin embargo, la perspectiva intercultural sitúa la convivencia entre diferentes en el centro de su programa. (Giménez, 2003, pág. 18)

Según expresa Ramírez, la interculturalidad se distinguiría del multiculturalismo sobre todo por sus objetivos: éste busca una convivencia entre culturas diversas, bajo el signo de la tolerancia; aquél intenta la convergencia entre tradiciones que eventualmente pueda desembocar en la unidad cultural. En este sentido, el multiculturalismo se muestra como una propuesta transitoria que permite lograr los objetivos radicales de la interculturalidad. (Ramírez, 2014, pág. 63)

Al respecto, Wierny argumenta que se debe construir una unidad que respete las diferencias, en vez de una diversidad que destruya la cohesión multigrupal. Apuntar a una interculturalidad que refuerce la integración eliminando los prejuicios y los estereotipos (Wierny, 2005, pág. 24). 
Esta apreciación o perspectiva parece haber sido considerada en la redacción de la constitución ecuatoriana vigente desde el año 2008, y auspiciada por el gobierno del economista Correa; cuerpo legal que puntualiza los derechos de las comunidades indígenas como una forma de reivindicarlos ante la mayoría mestiza y los grupos de poder. Se pretende un Estado orientado a la producción de verdadera justicia o se trata únicamente de un ofrecimiento de disculpas públicas y reparaciones en su contenido.

Si se considera lo expresado por Sandel, respecto que en algunos casos, cuando se intenta pedir perdón públicamente o reparar el mal infligido se puede hacer más daño que otra cosa, se inflaman viejas animadversiones, se consolidan las enemistades históricas, se enraíza el victimismo o se generan resentimientos. (Sandel, 2011) Aspectos que no deberían ser descuidados por la sociedad ecuatoriana, particularmente por quienes ejecutarán los programas previstos para alcanzar esas reivindicaciones y reparaciones a los grupos indígenas.

\section{La Constitución ecuatoriana vigente}

Una vez contextualizada la propuesta de investigación, se procederá entonces con el análisis de la carta magna ecuatoriana y su orientación entre el multiculturalismo y la interculturalidad.

La constitución ecuatoriana está compuesta por nueve títulos divididos en capítulos y secciones, totalizando cuatrocientos cuarenta y cuatro artículos. Si bien la carta magna ecuatoriana responde, y es consecuencia, de importantes demandas sociales globales de las últimas décadas que reclaman mayor flexibilización de las formas jurídicas y mayor participación política (Perette, 2011, pág. 12) Es precisamente en varios de sus títulos que se ha considerado una orientación intercultural, ya que como indica Giménez, esta perspectiva surge básicamente tras la constatación de los límites, fracasos y errores en el campo del multiculturalismo (Giménez, 2003, pág. 11).

En el Título I, Elementos Constitutivos del Estado, desde sus Principios fundamentales, el Ecuador se proclama como un Estado constitucional de derechos y justicia, social, democrático, soberano, independiente, unitario, intercultural, plurinacional y laico. Sin embargo, la posición de Peñalver por ejemplo, deja clara la crítica a las prácticas interculturales apoyadas sobre actitudes que sólo ocultan indiferencia cuando no dominación (Peñalver, 1996, pág. 38) Precisamente sobre estas prácticas se pretende ahondar en este ensayo.

La primera de estas prácticas interculturales radica en el reconocimiento del idioma, que en el caso ecuatoriano considera al castellano como su idioma oficial en el artículo 2 de la constitución, pero de inmediato se menciona que el castellano, el kichwa y el shuar son idiomas oficiales de relación intercultural. Sin embargo, en todo el territorio nacional el quichua y el shuar sólo son empleados por la población indígena, sin que exista la más mínima interacción con la población que tiene al castellano como lengua materna.

En cuanto a la nacionalidad ecuatoriana como vínculo jurídico político de las personas con el Estado, se indica en el artículo 6 que todas las ecuatorianas y los ecuatorianos son ciudadanos, sin perjuicio de su pertenencia a alguna de las nacionalidades indígenas que coexisten en el Ecuador plurinacional. Empero, ser miembro de alguna de las nacionalidades 
indígenas podría dar nacimiento a una "ciudadanía diferenciada", como señalaba Martínez, la que podría violar la igualdad al favorecer unos grupos frente a otros e irrespetar la neutralidad del Estado (Martínez, 1999, pág. 263).

En el Título II Derechos, capítulo segundo Derechos del Buen Vivir, sección tercera Comunicación e información, en su artículo 16 expresa que todas las personas, en forma individual o colectiva, tienen derecho a una comunicación libre, intercultural, incluyente, diversa y participativa, en todos los ámbitos de la interacción social, por cualquier medio y forma, en su propia lengua y con sus propios símbolos. Surge el interculturalismo como una manifestación de voluntad encaminada a lograr unas relaciones consideradas positivas, en un plano de mutua influencia (Gallego C. , 1994, pág. 201) como es el caso de la comunicación.

Continuando con los Derechos del Buen Vivir, en la sección quinta Educación, en el artículo 27 se establece que la educación se centrará en el ser humano y garantizará su desarrollo holístico, en el marco del respeto a los derechos humanos, al medio ambiente sustentable y a la democracia; será participativa, obligatoria, intercultural, democrática, incluyente y diversa, de calidad y calidez; impulsará la equidad de género, la justicia, la solidaridad y la paz; estimulará el sentido crítico, el arte y la cultura física, la iniciativa individual y comunitaria, y el desarrollo de competencias y capacidades para crear y trabajar.

En el siguiente artículo se expresa que la educación responderá al interés público y no estará al servicio de intereses individuales y corporativos, y que es derecho de toda persona y comunidad interactuar entre culturas y participar en una sociedad que aprende. El Estado promoverá el diálogo intercultural en sus múltiples dimensiones. Como menciona Galarza, debemos comprender que la interculturalidad sobrepasa a la educación, pero que de ninguna manera la minimiza o la excluye, sino que más bien ella es uno de los campos donde se expresan, por un lado, las contradicciones de los seres humanos como universales singulares; pero, por otro lado, es un espacio que abre la posibilidad del diálogo, el acuerdo, el respeto, la tolerancia, la equidad cultural. (Galarza, 2006, pág. 175)

En la sección séptima Salud, en el artículo 32 se menciona que la salud es un derecho que garantiza el Estado, cuya realización se vincula al ejercicio de otros derechos, entre ellos el derecho al agua, la alimentación, la educación, la cultura física, el trabajo, la seguridad social, los ambientes sanos y otros que sustentan el Buen Vivir. Además de expresar que la prestación de los servicios de salud se regirá por los principios de equidad, universalidad, solidaridad, interculturalidad, calidad, eficiencia, eficacia, precaución y bioética, con enfoque de género y generacional.

En suma, con los derechos del Buen Vivir, se espera señalar una de las dimensiones prácticas del multiculturalismo, la política de la diferencia que expone como reivindicaciones: La conformación de una estructura institucional que permita a una sociedad ciega a las diferencias, y por tanto discriminatoria, injusta e inhumana, valorar las identidades; La superación de una ciudadanía de segunda clase, configurada con base en un universalismo abstracto y formal; la condena de todas aquellas prácticas mediante las cuales los grupos dominantes tienden a afirmar su hegemonía inculcando una imagen de inferioridad a los subyugados; finalmente reivindicar a 
favor de las culturas su propia definición, así como su permanencia. (Ramírez, 2014, págs. 5253)

Estas reivindicaciones y reparaciones están claramente presentes en el capítulo cuatro, donde se encuentran consagrados derechos distintivos; la carta magna establece en su artículo 56 que las comunidades, pueblos, y nacionalidades indígenas, el pueblo afroecuatoriano, el pueblo montubio y las comunas forman parte del Estado ecuatoriano, único e indivisible. De inmediato instituye en el siguiente artículo, que se reconoce y garantizará a las comunas, comunidades, pueblos y nacionalidades indígenas, de conformidad con la Constitución y con los pactos, convenios, declaraciones y demás instrumentos internacionales de derechos humanos, los denominados derechos colectivos. El Estado garantizará la aplicación de estos derechos colectivos sin discriminación alguna, en condiciones de igualdad y equidad entre mujeres y hombres.

Todos estos derechos colectivos destinados a un grupo minoritario o étnico, los indígenas en este caso, en cierta medida ya predispone a entenderlo como jurídicamente segregado, a modo de una especie de estigma benigno que contiene el germen de su siempre potencial malignización (Delgado, 2004, pág. 101). Nos encontramos entonces con la antinomia entre el universalismo de los derechos y los derechos “particulares” de las minorías (Sánchez, 2003, pág. 176).

Estos derechos colectivos están consagrados en la constitución de manera específica para los pueblos ancestrales, indígenas, afroecuatorianos y montubios, quienes podrán constituir circunscripciones territoriales para la preservación de su cultura, según estipula el art. 60 .

Al citar los deberes y responsabilidades de las ecuatorianas y los ecuatorianos, sin perjuicio de otros previstos en la Constitución y la ley, se indica en el artículo 83 que se deberá promover la unidad y la igualdad en la diversidad y en las relaciones interculturales. Suena paradójico que se pida a "todos" la promoción de la unidad y la igualdad, pero existan los denominados derechos colectivos sólo para una parte de los connacionales.

Al referirnos al Título IV, Participación y Organización del Poder, en su capítulo primero, sección primera, artículo 95, se establecen los Principios de la participación, misma que se orientará por la igualdad, autonomía, deliberación pública, respeto a la diferencia, control popular, solidaridad e interculturalidad. Sin embargo, suele ser contraproducente la mención de diferencias, étnicas en especial, y la pretendida interacción cultural, ya que cada grupo etnocultural tenderá a evitar participar conjuntamente en la vida política del estado que los alberga (Wierny, 2005, pág. 20).

En el capítulo tercero, sección segunda artículo 156, se crean los Consejos nacionales para la igualdad como órganos responsables de asegurar la plena vigencia y el ejercicio de los derechos consagrados en la Constitución y en los instrumentos internacionales de derechos humanos, los mismos que ejercerán atribuciones en la formulación, transversalización, observancia, seguimiento y evaluación de las políticas públicas relacionadas con las temáticas de género, étnicas, generacionales, interculturales, y de discapacidades y movilidad humana, de acuerdo con la ley. Pero se deberá reconocer, como señala Galarza, que la igualdad del nivel de las culturas no elimina de ninguna manera, las raíces de las inequidades, que son originadas en la 
desigualdad económica, de género, educativa, de clase, regionales, etc. Por lo tanto, trabajar sobre la transformación/eliminación de las desigualdades, como fuentes de los conflictos sociales, es una de las tareas que posibilitan el desarrollo del proyecto humano de la interculturalidad, y de la paz. (Galarza, 2006, pág. 175)

Es ciertamente posible, mencionaría Sandel, que una convención más representativa hubiese producido una constitución más justa. Pero se trata de una mera cábala. No hay garantía alguna de que ningún contrato social o convención constituyente, por representativa que sea, produzca unos términos equitativos para regir la cooperación social. (Sandel, 2011) Cabe indicar que la nueva carta magna ecuatoriana ha sido calificada como justa y reivindicadora, especialmente por los pueblos y comunidades indígenas del país, de manera especial por la concesión y consagración de su propia justicia.

En el capítulo cuarto, sección segunda artículo 171, se proclama la Justicia indígena señalando que las autoridades de las comunidades, pueblos y nacionalidades indígenas ejercerán funciones jurisdiccionales, con base en sus tradiciones ancestrales y su derecho propio, dentro de su ámbito territorial, con garantía de participación y decisión de las mujeres. Las autoridades aplicarán normas y procedimientos propios para la solución de sus conflictos internos, y que no sean contrarios a la Constitución y a los derechos humanos reconocidos en instrumentos internacionales.

El Estado garantizará que las decisiones de la jurisdicción indígena sean respetadas por las instituciones y autoridades públicas. De esta forma, el Estado ecuatoriano cumple con una premisa fundamental del multiculturalismo normativo comunitarista que anhela y persigue la justicia a través de la protección política de las culturas, o, al menos, la justicia para los miembros de esas 'culturas', concebidas entonces, en general de forma laxa e indistinta, como comunidades, grupos sociales, étnicos o nacionales. (Fisher, 2009, pág. 34) Sin embargo, mencionaría Giovanni Sartori, la exacerbación de la diversidad o la tendencia a crear excepciones para el cumplimiento de la ley, fundamentadas en divergencias culturales, desvirtúa el carácter general de la norma, inundando la praxis de leyes sectoriales y desiguales. Sartori, como se citó en (Ramírez, 2014, pág. 61).

En el capítulo sexto Función Electoral, artículo 217 se indica que la función electoral garantizará el ejercicio de los derechos políticos que se expresan a través del sufragio, así como los referentes a la organización política de la ciudadanía. La función electoral estará conformada por el Consejo Nacional Electoral y el Tribunal Contencioso Electoral, órganos que se regirán por principios de autonomía, independencia, publicidad, transparencia, equidad, interculturalidad, paridad de género, celeridad y probidad.

Debiendo tener especial atención, menciona Fisher, en el surgimiento de derechos políticos especiales, que implican la exclusión de otros ciudadanos, derechos basados ya no sólo en la pertenencia a un grupo social (a una 'cultura'), sino de manera más radical e inadmisible, en la pertenencia étnica, racial y biológica (Fisher, 2009, pág. 38).

El referido autor nos indica además, que la discriminación social, la marginación económica y la exclusión política de grupos minoritarios son aristas -quizá las más graves- del 
problema de lograr una vida gregaria y cooperativa relativamente pacífica, estable y equitativa. Resolver ese problema, que es un problema de justicia, requiere cambiar (corregir), si es necesario por la fuerza pública legítimamente constituida, la conducta del agente discriminador, del marginador o del excluidor, así como los resultados de esa conducta sobre el medio ambiente físico y simbólico; y de ninguna manera 'proteger la cultura' del marginado, excluido o discriminado. (Fisher, 2009, pág. 43)

En el Título V Organización Territorial del Estado, capítulo segundo artículo 242, se indica que el Estado se organiza territorialmente en regiones, provincias, cantones y parroquias rurales. Por razones de conservación ambiental, étnico-culturales o de población podrán constituirse regímenes especiales. Los distritos metropolitanos autónomos, la provincia de Galápagos y las circunscripciones territoriales indígenas y pluriculturales serán regímenes especiales.

Se articula además que los cantones cuyos territorios se encuentren total o parcialmente dentro de una franja fronteriza de cuarenta kilómetros, recibirán atención preferencial para afianzar una cultura de paz y el desarrollo socioeconómico, mediante políticas integrales que precautelen la soberanía, biodiversidad natural e interculturalidad. La ley regulará y garantizará la aplicación de estos derechos.

Tal como_mencionara Kymlicka al referirse al acomodo de los grupos etnoculturales, en la mayoría de los estados multinacionales las naciones que los componen tienden a exigir alguna forma de autonomía política o de jurisdicción territorial que asegure el desarrollo pleno y libre de sus culturas y promueva los intereses de sus pueblos. (Kymlicka, 1996, pág. 29); Tal como en esta oportunidad satisface la carta magna ecuatoriana.

Pero una mayor reparación y resarcimiento se expresa en el capítulo tercero, respecto a Gobiernos autónomos descentralizados y regímenes especiales, según el art. 257 en el marco de la organización político administrativa podrán conformarse circunscripciones territoriales indígenas o afroecuatorianas, que ejercerán las competencias del gobierno territorial autónomo correspondiente, y se regirán por principios de interculturalidad, plurinacionalidad y de acuerdo con los derechos colectivos.

Además, las parroquias, cantones o provincias conformados mayoritariamente por comunidades, pueblos o nacionalidades indígenas, afroecuatorianos, montubios o ancestrales podrán adoptar este régimen de administración especial, luego de una consulta aprobada por al menos las dos terceras partes de los votos válidos. Dos o más circunscripciones administradas por gobiernos territoriales indígenas o pluriculturales podrán integrarse y conformar una nueva circunscripción. O sea, se pretende terminar haciendo de la "nacionalidad", un privilegio que recalifica moralmente la significación de los actos; es decir, que rompe la igualdad ante la ley (Monleón, 2002, pág. 32). Por tanto, las nacionalidades indígenas, los afroecuatorianos o los montubios del litoral, están siendo privilegiados por regímenes especiales que les permitirán incluso nuevas demarcaciones territoriales.

Como indica Cossío, respecto a una de las formas más relevantes del multiculturalismo, el indigenismo, que ha logrado en el caso del Ecuador, llevar a cabo las demandas para lograr 
que aquel que está en una posición de dominio, comience por aceptar su diferencia, su autonomía, logrado lo cual se podrán insertar en una nueva posición y jerarquía dentro del orden jurídico que continúa siendo dominante. Como puede verse, este complejo trayecto no inicia con las reivindicaciones jurídicas, sino que precisamente concluye con la juridificación de sus elementos distintivos, aquellos que les permitieron su diferenciación cultural respecto de otros colectivos. (Cossío, 2000, pág. 89)

Al referirse al Régimen de Desarrollo, en su Título VI, capítulo primero artículo 275, se expresa que el Estado planificará el desarrollo del país para garantizar el ejercicio de los derechos, la consecución de los objetivos del régimen de desarrollo y los principios consagrados en la Constitución. El Buen Vivir requerirá que las personas, comunidades, pueblos y nacionalidades gocen efectivamente de sus derechos, y ejerzan responsabilidades en el marco de la interculturalidad, del respeto a sus diversidades, y de la convivencia armónica con la naturaleza. Nuevamente podemos notar la contribución de la perspectiva intercultural referida anteriormente, al hacer énfasis en el requerimiento a todas las personas, comunidades, pueblos y nacionalidades para que alcancen el Buen Vivir o Sumak Kawsay.

Precisamente en el Título VII sobre el Régimen del Buen Vivir mencionado en párrafo anterior, se enuncia en el capítulo primero Inclusión y Equidad en su artículo 340, que el sistema nacional de inclusión y equidad social es el conjunto articulado y coordinado de sistemas, instituciones, políticas, normas, programas y servicios que aseguran el ejercicio, garantía y exigibilidad de los derechos reconocidos en la Constitución y el cumplimiento de los objetivos del régimen de desarrollo. Sistema que se guiará por los principios de universalidad, igualdad, equidad, progresividad, interculturalidad, solidaridad y no discriminación.

Surge así, en estos principios consagrados en la Constitución ecuatoriana, el fondo de la discusión acerca de lo multicultural de nuestras culturas, desde un punto de visto político y social, pero también ético, uno de los ideales ilustrados que más fuerza y potencia ha tenido en la modernidad: el principio de igualdad. Y frente a él el principio de la diferencia. (Peñalver, 1996, pág. 32)

En el mismo capítulo, en la sección primera al respecto de la educación, indica el artículo 343 que el sistema nacional de educación tendrá como finalidad el desarrollo de capacidades y potencialidades individuales y colectivas de la población, que posibiliten el aprendizaje, y la generación y utilización de conocimientos, técnicas, saberes, artes y cultura. Y que este sistema integrará una visión intercultural acorde con la diversidad geográfica, cultural y lingüística del país, y el respeto a los derechos de las comunidades, pueblos y nacionalidades.

Esta visión intercultural contempla, tal como menciona Ramírez, la práctica de la interculturalidad como medio para conservar, y en todo caso proteger, no son sólo las culturas y las identidades en sí mismas, sino los espacios de comunicación e intercambio entre ellas (Ramírez, 2014, pág. 75).

Para el cumplimiento de esta práctica, será responsabilidad del Estado indica el artículo 347, garantizar el sistema de educación intercultural bilingüe, en el cual se utilizará como lengua principal de educación la de la nacionalidad respectiva y el castellano como idioma de relación 
intercultural, bajo la rectoría de las políticas públicas del Estado y con total respeto a los derechos de las comunidades, pueblos y nacionalidades.

En la segunda sección, respecto de la salud en el régimen del Buen Vivir, indica el artículo 358 que el sistema nacional de salud tendrá por finalidad el desarrollo, protección y recuperación de las capacidades y potencialidades para una vida saludable e integral, tanto individual como colectiva, y reconocerá la diversidad social y cultural. El sistema se guiará por los principios generales del sistema nacional de inclusión y equidad social, y por los de bioética, suficiencia e interculturalidad, con enfoque de género y generacional. En la sección cuarta, sobre Hábitat y vivienda, el artículo 375 expresa que el Estado, en todos sus niveles de gobierno, garantizará el derecho al hábitat y a la vivienda digna, para lo cual elaborará, implementará y evaluará políticas, planes y programas de hábitat y de acceso universal a la vivienda, a partir de los principios de universalidad, equidad e interculturalidad, con enfoque en la gestión de riesgos.

En la quinta sección, Cultura, el artículo 377 menciona que el sistema nacional de cultura tiene como finalidad fortalecer la identidad nacional; proteger y promover la diversidad de las expresiones culturales; incentivar la libre creación artística y la producción, difusión, distribución y disfrute de bienes y servicios culturales; y salvaguardar la memoria social y el patrimonio cultural. Se garantiza el ejercicio pleno de los derechos culturales.

El siguiente artículo indica que el Estado ejercerá la rectoría del sistema a través del órgano competente, con respeto a la libertad de creación y expresión, a la interculturalidad y a la diversidad; será responsable de la gestión y promoción de la cultura, así como de la formulación e implementación de la política nacional en este campo. El reconocimiento del sustrato cultural de la identidad del ser humano: el desarrollo de tal identidad no es un proceso que se agote en la intimidad del individuo, aisladamente considerado, sino en comunicación con otros, particularmente a través de los elementos que, para tal efecto, aporta una cultura concreta. (Ramírez, 2014, pág. 51)

Sin embargo, deberá considerarse que el reconocimiento unidireccional corre el riesgo de no ser nunca suficiente; de ser considerado una ofensa más de la cultura dominante o, quizá peor, de convertirse en un instrumento que revitaliza o fortalece divisiones comunitarias latentes o en vía muerta. (Forte, 2007, pág. 618)

Cabe mencionar lo expresado por Ruiz acerca del "respeto" a esas culturas, que se alega para introducir diferencias, pero lo cierto es que así se está quebrando el presupuesto de la propia idea de constitución, la igualdad jurídica de los ciudadanos (Ruiz, 2001, pág. 21). Finalmente, en el Título VIII Relaciones Internacionales, capítulo primero, Principios de las Relaciones Internacionales, en su artículo 416 se expresa que las relaciones del Ecuador con la comunidad internacional responderán a los intereses del pueblo ecuatoriano, al que le rendirán cuenta sus responsables y ejecutores, y en consecuencia se promueve la conformación de un orden global multipolar con la participación activa de bloques económicos y políticos regionales, y el fortalecimiento de las relaciones horizontales para la construcción de un mundo justo, democrático, solidario, diverso e intercultural. 
Y en el capítulo tercero Integración latinoamericana, en el artículo 423 se indica que la integración, en especial con los países de Latinoamérica y el Caribe será un objetivo estratégico del Estado. En todas las instancias y procesos de integración, el Estado ecuatoriano se comprometerá a proteger y promover la diversidad cultural, el ejercicio de la interculturalidad, la conservación del patrimonio cultural y la memoria común de América Latina y del Caribe, así como la creación de redes de comunicación y de un mercado común para las industrias culturales.

Como puede distinguirse, la exposición de cada uno de los títulos constitucionales muestra la perspectiva intercultural revelada e implementada por una abrumadora mayoría de asambleístas constituyentes provenientes del mismo partido político del presidente Correa, quien ofreció como candidato, una reivindicación integral para los grupos vulnerables, en especial para las comunidades indígenas.

\section{Conclusiones}

La Constitución ecuatoriana orientada en propiciar las prácticas interculturales profundiza en la consagración de derechos colectivos especialmente para aquellos grupos poblacionales considerados vulnerables, de manera puntual en el caso de la población indígena nacional. Sin embargo esta misma población indígena continúa siendo discriminada y marginada. Quizás, con sólo mencionar que este colectivo ecuatoriano presenta según datos del último censo nacional, la tasa de analfabetismo más alta entre toda la población, se pueda tener noción de la situación por la que continúan atravesando.

Un cuerpo legal que identifica al país como un Estado de derechos e intercultural, nos permite apreciar la consciente orientación marcada por la transición entre el multiculturalismo y la interculturalidad, vista esta última como una representación superadora. La carta magna ecuatoriana tan extensa con sus más de cuatrocientos cuarenta artículos, puntualiza en los derechos colectivos de diversos grupos vulnerables, en especial de los indígenas, quienes integran una población cercana al millón de personas, que permanecen en espera de alcanzar una convivencia equitativa y que las reivindicaciones propuestas por el Estado nacional se cristalicen en acciones concretas para su beneficio.

La Constitución nacional que consagra los derechos de las ecuatorianas y los ecuatorianos y de manera concreta los derechos de las comunidades más vulnerables, puede ser considerada un buen inicio, que presupone grandes esfuerzos para que sus ciudadanos alcancen el Buen Vivir, pero no se podría dejar de puntualizar que quienes conforman las nacionalidades indígenas continúan en espera de justicia e igualdad, para realmente poder consumar el lema de su presentación "Dejemos el pasado atrás".

\section{Bibliografía}

Cossío, J. (2000). Constitucionalismo y Multiculturalismo. Isonomía, 75-93.

Delgado, M. (2004). Multiculturalismo y Sociedad. La diversidad cultural y sus usos. Pasajes, 97-110.

Devia, H., \& Romero, L. (2015). Elementos claves para la construcción de una teoría política multicultural desde el pensamiento de Charles Taylor. Nuevo Derecho, 131-139. 
Fisher, J. (2009). Multiculturalismo y ciudadanía. Factótum, 34-45.

Forte, J. (2007). Multiculturalismo, identidad y reconocimiento. Thémata, 613-618.

Galarza, G. (2006). Del multiculturalismo al interculturalismo universitario ecuatoriano. Revista Interuniversitaria de Formación del Profesorado, 163-178.

Gallego, C. (1994). Diversidad y multiculturalismo. Reflexiones desde la antropología. Acciones e Investigaciones Sociales, 195-205.

Giménez, C. (2003). Pluralismo, Multiculturalismo e Interculturalidad. Educación y Futuro, 9-26.

Kymlicka, W. (1996). Federalismo, nacionalismo y multiculturalismo. Revista internacional de filosofía política, 20-54.

Kymlicka, W. (Abril de 2001). Pensar el multiculturalismo. (Iconos, Entrevistador)

Kymlicka, W. (2007). Multiculturalismo. Diálogo Político, 11-35.

Martínez, F. (1999). Multiculturalismo y Nueva Ciudadanía. Laguna, 261-268.

Monleón, J. (2002). Sobre el multiculturalismo: una polémica esclarecedora. Cuadernos del Ateneo, 26-32.

Peñalver, C. (1996). Multiculturalismo y Tolerancia. Cuestiones Pedagógicas, 29-38.

Perette, C. (2011). La constitución multicultural, el Estado de derecho y la flexibilización de las formas jurídicas. Breve reseña de la justicia indígena del pueblo Chibuleo en Ecuador. Derecho y Ciencias Sociales, 3-29.

Ramírez, H. (2014). Praxis de la interculturalidad: los retos del multiculturalismo y el ethos del mestizaje. Persona y Derecho, 47-75.

Ruiz, C. (2001). Multiculturalismo y Constitución. Cuadernos Const. de la Cátedra Fadrique Furió Ceriol, 5-22.

Sánchez, I. (2003). Integración o Multiculturalismo. Persona y Derecho, 163-183.

Sandel, M. (2011). Justicia ¿Hacemos lo que debemos? Barcelona: Debate.

Wierny, S. (2005). La invención del multiculturalismo. Tinkuy -Boletín de investigación y debate-, 1525.

Zizek, S. (1998). Multiculturalismo o la lógica cultural del capitalismo multinacional. En F. Jameson, \& S. Zizek, Estudios Culturales. Reflexiones sobre el multiculturalismo (págs. 137-188). Buenos Aires: Paidós. 